\title{
"Y LA VIDA SE HIZO CONCEPTO". HEGEL Y EL FINAL DE LA FILOSOFÍA COMO METAFÍSICA
}

Carlos Gutiérrez Lozano*

RESUMEN: En este texto, el autor sintetiza la aportación más destacable, a su juicio, de Hegel. De $L a$ fenomenología del Espíritu a La ciencia de la Lógica abarca el recorrido del pensamiento hegeliano, hasta la consumación de la metafísica: con la lógica vuelve, en la idea absoluta, a la pura inmediación del ser.

Palabras Clave: Concepto, idea, Hegel, metafísica, Fenomenología del Espíritu, Ciencia de la Lógica.
ABSTRACT: In this text, the author summarizes what he believes to be Hegel's most notable contribution. From The Phenomenology of Spirit to The Science of Logic he covers Hegelian philosophy to the consummation of metaphysics: with logic he returns as an absolute concept to the pure immediacy of being.

KEYWORDS: concept, idea, Hegel, metaphysics, The Phenomenology of Spirit, The Science of Logic.
* Departamento Académico de Estudios Generales, ITAM. 


\author{
"Y LA VIDA SE HIZO CONCEPTO". \\ HEGEL Y EL FINAL DE LA FILOSOFÍA \\ COMO METAFÍSICA
}

\section{Introducción}

Karl-Heinz Volkmann-Schluck apunta en su libro sobre Hegel ${ }^{1}$ que la totalidad del sistema hegeliano está ya contenida en un escrito de juventud, a saber Diferencia entre los sistemas de filosofía de Fichte y Schelling de 1801. Ahí determina Hegel la tarea y función de toda filosofía: "superar las finitudes de la conciencia y construir lo absoluto en la conciencia".

Al observar esta frase, se ve inmediatamente que lo absoluto está presente desde el inicio en el pensamiento de Hegel. Y es que lo absoluto no es más

${ }^{1}$ Karl-Heinz Volkmann-Schluck, Hegel. Die Vollendung der abendlänsichen Metaphysik, 1998, Würzburg, Königshausen \& Neumann. En lo que sigue nos basamos en la exposición introductoria de este libro. Las traducciones de este texto son mías. que la totalidad de aquello que existe de manera ilimitada. Y esto que existe de manera ilimitada es para Hegel, continuando la herencia moderna desde Descartes y hasta Kant, la unidad de subjetividad y objetividad. Pues lo subjetivo es aquello que se relaciona consigo mismo, mientras que lo objetivo es lo que se relaciona con el sujeto. Pero entonces lo absoluto es la unidad de aquello que aparece como contrapuesto, como contrario. Y entonces tenemos que lo absoluto, como unidad de subjetividad y objetividad en cuanto contrapuestos, incluye la negación en sí misma, ya que la subjetividad es al mismo tiempo la negación de la objetividad y ésta es al mismo tiempo la negación de aquélla. 
Con lo anterior, Hegel reasume y supera aquella vieja controversia, nunca satisfactoriamente resuelta, sobre el ser entre Parménides y Heráclito. Si bien Platón proponía que entre el ser y el no ser hay una mediación y Aristóteles proponía el movimiento con sus componentes metafísicos de potencia y acto, no es sino Hegel quien plantea la cuestión de fondo e intenta resolverla poniendo lo absoluto como unidad que incluye positivamente la negación en sí misma.

Ahora bien, si lo absoluto es la unidad de aquello contrapuesto, tenemos por un lado lo que une y por otro lado lo que separa. Según Hegel, como para Kant, en el hombre existen facultades para captar lo que une y lo que separa. La facultad que une, y por tanto la facultad para lo absoluto, es la razón, mientras que la facultad que separa es la inteligencia o el entendimiento. Hegel escribe en la Fenomenología del espíritu: "la actividad del separar es la fuerza y la labor del entendimiento, de la más grande y maravillosa de las potencias o, mejor dicho, de la potencia absoluta".2

Hegel constata que nuestro comportamiento más elemental, en el que nos encontramos desde siempre, es el de separar y distinguir, o sea,

${ }^{2}$ Hegel, Fenomenología del Espíritu, 1987, México, FCE, tr. Wenceslao Roces, p. 23. siempre nos encontramos en el campo de la inteligencia. Y la inteligencia en cuanto que pone lo separado siempre relacionado con el ser, no alcanza nunca la unidad y se mueve únicamente en el campo de lo finito. Por ello la filosofía es un rebasar el campo de la inteligencia para acceder al campo de la razón y pasar de lo separado a la unidad. Con otras palabras:

Porque nuestra conciencia primera y mayormente se instala y se mueve en finitudes, por ello la tarea de la filosofía debe ser determinada en superar las finitudes de la conciencia y construir lo absoluto en la conciencia como un todo que contiene en sí lo puesto y lo contrapuesto, como aquello que es verdadero y real. ${ }^{3}$

Al reflexionar acerca de lo que une y de lo que separa, Hegel cae en la cuenta de que esa es una característica fundamental de la vida: la vida contiene en sí lo que une y lo que separa. Del mismo modo, en la vida están presentes tanto la inteligencia como la razón. De tal manera que vida es otra palabra empleada por Hegel para nombrar lo absoluto.

El separarse de la unidad es lo que hace que "aparezca", que sea la vida; pero la vida se manifiesta en grado

\footnotetext{
${ }^{3}$ Volkmann-Schluck, op. cit., p. 13.
} 
sumo cuando detrás y encima de las divisiones recobra su unidad. Tanto en la vida como en lo absoluto, unidad y división son inseparables. Pero dado que en la vida domina normalmente la inteligencia y su capacidad separadora, se hace necesaria la filosofía para construir o restablecer la unidad, puesto que la división puede hacer perder de vista su origen, a saber, lo absoluto como la unidad de todo. Así pues, la filosofía es una necesidad de la vida misma y, por ello, la filosofía no puede sino estar al servicio de la vida.

Ahora bien, si la vida es en sí misma unidad y separación, entonces la vida es movimiento, pues sólo se mueve aquello en que hay separación y contraposición. Y si hay movimiento, entonces la vida es esencialmente devenir, hacerse, llegar a ser. Para Hegel, el devenir es un concepto fundamental para caracterizar lo absoluto y la vida. Lo absoluto y la vida son en tanto devienen, su devenir es su ser.

¿Dónde encuentra Hegel la herramienta necesaria para pensar el devenir, el movimiento que encierra en sí mismo la negación, la contraposición entre lo objetivo y lo subjetivo? La inteligencia no puede ser herramienta adecuada, pues ella sólo piensa la separación y la diferencia. Así que únicamente queda la razón. Pero la razón debe tener una característica muy definida para que pueda realizar tal función: si la razón es la facultad que une las diferencias en la unidad, entonces la razón sólo puede ser reflexión de la unidad del todo sobre sí misma. Tal reflexión lleva la unidad de lo subjetivo y lo objetivo, de lo finito y lo infinito a lo absoluto, le confiere su carácter de absolutidad. $\mathrm{Y}$ a este elevarse reflexionante de la razón a la conciencia, Hegel le llama saber: "esta identidad consciente de lo finito y lo infinito, la unificación de ambos mundos, del sensible y del intelectual, del necesario y del libre en la conciencia es saber". ${ }^{4}$ El saber que se sabe a sí mismo como unidad de lo diferente y de lo idéntico en movimiento dialéctico es lo que Hegel llama espíritu, el espíritu absoluto.

A partir de las consideraciones tempranas aludidas, Hegel llevará a cabo con admirable precisión y coherencia el plan trazado. De ahí que en lo siguiente se analicen algunas partes fundamentales de las dos obras principales de Hegel: La fenomenología del espíritu y La ciencia de la lógica. La enciclopedia de las ciencias filosóficas no será tratada por ser más bien de carácter pedagógico, es decir, por hacer asequible el todo del sistema hegeliano de manera más comprensible para los oyentes de sus clases.

\footnotetext{
${ }^{4}$ Ibid., p. 40. (Traducción mía).
} 


\section{Fenomenología del espíritu}

Hegel habla de la inutilidad de los prólogos; sin embargo, aprovecha la oportunidad para hacer varias aclaraciones que serán de importancia fundamental para la realización de su proyecto filosófico. En primer lugar, afirma que es falsa la apariencia de que en la filosofía la cosa misma sólo se da en los resultados o al final, mientras que el desarrollo carece de importancia. ${ }^{5}$ Además, también es un error el que los sistemas filosóficos vean únicamente la contradicción en la diversidad de opiniones o posturas. ${ }^{6}$ Hegel apunta a algo nuevo cuando, buscando superar las malas interpretaciones anteriores, afirma que "la cosa no se reduce a su fin, sino que se halla en su desarrollo, ni el resultado es el todo real, sino que lo es en unión con su devenir". ${ }^{7}$ Además, las contradicciones son momentos necesarios para el desarrollo de las cosas.

Por otro lado, Hegel define claramente el proceso a seguir en su exposición: superando la inmediatez de la vida, hay que iniciar en el pensamiento de la cosa en general para pasar enseguida a la experiencia de la cosa misma en vistas a llegar al momento final, a saber: "que la seriedad del concepto penetre en la profundi-

${ }^{5}$ Cfr. Hegel, op. cit., p. 7.

${ }^{6}$ Cfr. ibid., p. 8.

${ }^{7}$ Ibidem. dad de la cosa". ${ }^{8}$ Aquí puede verse con claridad el contorno del método dialéctico hegeliano.

Pero lo que interesa a Hegel no es tener una verdad sobre alguna cosa o muchas verdades sobre muchas cosas. Para él, la verdad sólo puede surgir cuando se tiene el saber ordenado sobre la totalidad. Y a ese saber ordenado Hegel le llama ciencia. Por eso, Hegel se propone "contribuir a que la filosofía se aproxime a la forma de ciencia -a la meta en que pueda dejar de llamarse amor por el saber para llegar a ser saber real". ${ }^{9}$ A pesar de las dificultades que surgen con la afirmación anterior, sobre todo a causa del uso cotidiano del término ciencia, el cual piensa normalmente en las ciencias particulares, Hegel insiste en que "la verdad sólo tiene en el concepto el elemento de su existencia". ${ }^{10}$ Profundiza estas ideas y perfila muy claramente su intento filosófico, pues éste consiste en captar conjuntamente lo que en toda la historia de la filosofía se había considerado como separado, es más, como contrapuesto: "todo depende de que lo verdadero se no aprehenda y se exprese como sustancia, sino también y en la misma medida como sujeto". ${ }^{11}$ Que la sustancia llegue a ser sí misma y que el sujeto se comprenda en cuanto unidad

\footnotetext{
${ }^{8}$ Ibid., p. 9.

${ }^{9}$ Ibidem.

${ }^{10}$ Ibidem.

${ }^{11}$ Ibid., p. 15.
} 
que posee en sí la diferencia, tal es el inédito intento que emprende Hegel, el cual no puede ser llevado a cabo sin el método que implique en sí mismo la negatividad, es decir, el movimiento dialéctico. Hegel abunda:

Lo verdadero es solamente esta igualdad que se restaura o la reflexión en el ser otro en sí mismo, y no una unidad originaria en cuanto tal o una unidad inmediata en cuanto tal. Es el devenir de sí mismo, el círculo que presupone y tiene por comienzo su término como su fin y que sólo es real por medio de su desarrollo y de su fin. ${ }^{12}$

De lo anterior se sigue que lo absoluto, como unidad diferenciada es un principio que sólo se obtiene al final, es "resultado" del movimiento que se pone a sí mismo en marcha. Lo absoluto es devenir dialéctico que incluye desde siempre en sí mismo el principio y el fin, sin que el desarrollo sea menos importante. Para que todo lo anterior no sea tomado como una serie de afirmaciones contradictorias entre sí, Hegel reasume y explica en un nuevo sentido el término mediación: "la mediación no es sino la igualdad consigo misma en movimiento o la reflexión en sí misma, el momento del yo que es para sí, la pura negatividad o, reducida a su abstracción pura, el simple devenir". ${ }^{13}$

${ }^{12}$ Ibid., p. 16

${ }^{13}$ Ibid., p. 17.
Lo anterior implica de suyo que el devenir contiene en sí mismo el principio, el desarrollo o mediación y el fin. Esto, según Hegel, está en consonancia con el principio de finalidad, ya que el devenir es al mismo tiempo la realidad en sí: "lo real es lo mismo que su concepto simplemente porque lo inmediato, en cuanto fin, lleva en sí el sí mismo o la realidad pura". ${ }^{14}$

De esto Hegel deduce coherentemente que el saber real sólo puede ser concebido y expresado como ciencia o sistema. Y sólo a esto es a lo que Hegel llama espíritu: "el que lo verdadero sólo es real como sistema o el que la sustancia es esencialmente sujeto se expresa en la representación que enuncia, lo absoluto como espíritu, el concepto más elevado de todos". ${ }^{15}$ Hegel añade las características del espíritu: "Pero este ser en sí y para sí es primeramente para nosotros lo en sí, es la sustancia espiritual"16. Y precisa:

Es para sí solamente para nosotros, en cuanto que su contenido espiritual es engendrado por él mismo; pero en cuanto que es para sí también para sí mismo, este autoengendrarse, el concepto puro, es para él, al mismo tiempo, el elemento objetivo en el que tiene su existencia; $y$, de este modo, en su existen-

\footnotetext{
${ }^{14}$ Ibidem.

${ }^{15}$ Ibid., p. 19.

${ }^{16}$ Ibidem.
} 
cia, es para sí mismo objeto reflejado en sí. ${ }^{17}$

El espíritu, pues, tiene que escapar tanto a la inmediatez propia de la intuición sensible como a la rigidez de los pensamientos fijos; esta tarea es ardua y difícil, pero Hegel ve en el movimiento dialéctico el método seguro para avanzar el camino que lleva del espíritu en sí, que piensa pensamientos vacíos, al espíritu en sí y para sí, que lleva en sí mismo el movimiento total del espíritu absoluto: "a través de este movimiento, los pensamientos puros devienen conceptos y sólo entonces son lo que son en verdad, automovimientos, círculos; son lo que su sustancia es, esencialidades espirituales". ${ }^{18}$

Esta constitución de la filosofía se afianza cuando se le compara con otras formas de saber, por ejemplo, el saber histórico o el matemático. Según Hegel, la matemática trabaja con determinaciones no esenciales de las cosas (el espacio y el uno), mientras que en la filosofía "su elemento y su contenido no son lo abstracto o irreal, sino lo real, lo que se pone a sí mismo y vive en sí, el ser ahí en su concepto". ${ }^{19}$ La filosofía hegeliana es la ciencia en que la vida se hace concepto y alcanza así su plenitud. ${ }^{20}$

${ }^{17}$ Ibidem .

${ }^{18}$ Ibid., p. 25.

${ }^{19}$ Ibid., p. 32.

20 "La ciencia sólo puede, lícitamente, organizarse a través de la vida propia del concepto", ibid., p. 35.
Del mismo modo, Hegel distingue con claridad el saber filosófico del saber del sentido común. La diferencia estriba en que el saber filosófico es el saber del concepto especulativo. Y semejante concepto especulativo es aquel que se encierra en la lógica. Al respecto, escribe:

En esta naturaleza de lo que es que consiste en ser en su ser su concepto, reside en general la necesidad lógica; sólo ella es lo racional y el ritmo del todo orgánico, y es precisamente saber del contenido en la misma medida en que el contenido es concepto y esencia $\mathrm{o}$, dicho en otros términos, solamente ella es lo especulativo. ${ }^{21}$

Después del prólogo, Hegel habla en la introducción de la experiencia y enseguida desarrolla el despliegue de las configuraciones de la conciencia hasta alcanzar el saber absoluto. En el saber absoluto se ha logrado, según Hegel, la unificación en la conciencia de la sustancia y el sujeto. Esta unidad es

la que cierra esta serie de las configuraciones del espíritu; pues en ella el espíritu llega a saberse no sólo como es en sí o según su contenido absoluto, ni tampoco como es para sí según su forma carente de contenido, o según el lado de la autoconciencia, sino como es en sí y para si. ${ }^{22}$

${ }^{21}$ Ibid., p. 38.

${ }^{22}$ Ibid., p. 464. 
Tal unidad se ha alcanzado en el concepto:

Esta última figura del espíritu, el espíritu que da a su completo y verdadero contenido, al mismo tiempo, la forma del sí mismo y que, con ello, realiza [realisiert] su concepto a la par que en esta realización [Realisierung] permanece en su concepto, es el saber absoluto; es el espíritu que se sabe en la figura de espíritu o el saber conceptual. ${ }^{23}$

Finalmente, el espíritu, en tanto que saber que une las diferencias en la pura especulación del concepto, alcanza la meta anhelada: el espíritu "es en sí el movimiento que es el conocer-la transformación de aquel en sí en el para sí, de la sustancia en el sujeto, del objeto de la conciencia en objeto de la autoconciencia, es decir, en un objeto asimismo superado o en el concepto". ${ }^{24}$

De ahí que se pueda decir lo siguiente:

Podemos afirmar que el proyecto fundamental de la filosofía hegeliana consiste precisamente en la búsqueda $[. .$.$] de un principio unifi-$ cador y comprehensivo a partir del cual se hiciera posible la superación de aquella escisión de la vida humana que Hegel sintetiza en la oposición de sujeto y objeto. Él encuentra ese camino -y con ello formula el núcleo más original de su pensamiento-

${ }^{23}$ Ibid., p. 467.

${ }^{24}$ Ibid., p. 469. cuando establece y desarrolla la noción del concepto especulativo (Begriff), en torno a la cual se articula el conjunto de su filosofía. ${ }^{25}$

Con todo, la Fenomenología del espíritu constituye únicamente el paso previo necesario para tal despliegue dialéctico, en cuanto que describe los movimientos de la conciencia para llegar a ser sí misma, es decir, en cuanto que la conciencia llega a ser saber de sí, pero un saber de sí carente aún de contenido. Hegel escribe:

Tal vez podría considerarse necesario decir de antemano algo más de cerca de los diversos aspectos del método de este movimiento o de la ciencia. Pero su concepto va ya implícito en lo que hemos dicho y su exposición corresponde propiamente a la lógica o es más bien la lógica misma. ${ }^{26}$

Y en otro pasaje afirma:

El ser es absolutamente mediado - es contenido sustancial, que de un modo no menos inmediato es patrimonio del yo, es sí mismo o el concepto. Al llegar aquí, termina la Fenomenología del Espiritu. Lo que el espíritu se prepara en ella es el elemento del saber [...] Su movimiento, que se organiza en este

${ }^{25}$ Eduardo Álvarez, El saber del hombre. Una introducción al pensamiento de Hegel, 2001, Madrid, Trotta, p. 18-9.

${ }^{26} \mathrm{Hegel}$, Fenomenología del Espiritu, op. cit., p. 32 . 
elemento como un todo, es la Lógica o Filosofia especulativa. ${ }^{27}$

\section{La ciencia de la Lógica}

Es la obra más especulativa y filosófica de Hegel. Aquí desarrolla lo que será la primera parte de su sistema absoluto del saber universal, puesto que a la lógica le seguirán la filosofía de la naturaleza y la filosofía del espíritu. ${ }^{28}$ La ciencia de la Lógica está dividida en tres partes: la doctrina del ser, la doctrina de la esencia y la doctrina del concepto. A su vez, la doctrina del concepto está subdividida en el concepto subjetivo, el concepto objetivo y la idea. Finalmente, la idea tiene las divisiones de la vida, el conocimiento y la idea absoluta.

Para Hegel, la doctrina del concepto tiene como momentos dialécticos anteriores el ser y la esencia, de manera que éstos están presentes en el concepto pero no ya como ellos mismos, sino precisamente en cuanto que han llegado a su unidad y conciencia en el concepto. Hegel escribe:

El concepto ante todo debe ser considerado en general como el tercero con respecto al ser y la esencia,

${ }^{27}$ Ibid., p. 26.

${ }^{28}$ De este plan sólo se publicó la Lógica. La filosofía de la naturaleza y del espíritu sólo aparecen en La enciclopedia de las ciencias filosóficas. esto es a lo inmediato y la reflexión. Ser y esencia, por lo tanto, son los momentos de su devenir; pero él es la base y verdad de ellos, considerada como identidad, donde ellos han perecido y están contenidos. ${ }^{29}$

Con otras palabras, la esencia es la negación de la inmediatez del ser y esto hace que se manifieste como apariencia, y el concepto es la negación de la negación, es decir, la absoluta negatividad donde alcanza el ser su unidad en sí y por sí mismo. ${ }^{30}$ Además, los momentos del ser y de la esencia constituyen la sustancia real, pero substancia que aún está contrapuesta al sujeto. Sólo en el concepto la sustancia real llega a ser idéntica con el sujeto. ${ }^{31}$ Así, en el concepto parece cumplirse la tarea anunciada por Hegel en la Fenomenología del espiritu.

La filosofía de Hegel puede verse como el final de la filosofía como metafísica, si se analiza su posición respecto a las filosofías metafísicas tradicionales que separaban los dos polos que Hegel quiere unir: la filosofía de la sustancia de Spinoza y la filosofía del sujeto de Kant. En ambos casos, Hegel afirma que la única manera de superar ambos sistemas es elevándolos hasta sus últimas con-

\footnotetext{
${ }^{29}$ Hegel, Ciencia de la Lógica, 1968, Buenos Aires, Ediciones Solar, tr. Augusta y Rodolfo Mondolfo, vol. 2, p. 249.

${ }^{30}$ Cfr. ibid., p. $272-4$.

${ }^{31}$ Cfr. ibid., p. 252s.
} 
secuencias. Respecto de Spinoza, Hegel afirma:

La única confutación del espinosismo, puede consistir sólo en que su punto de vista, sea, primeramente, reconocido como esencial y necesario; pero, que, en segundo lugar, este punto de vista sea llevado a partir de sí mismo hacia un punto de vista más elevado. La relación de sustancialidad, considerada total y solamente en sí y por sí misma se transporta hacia su opuesto, es decir, hacia el concepto. ${ }^{32}$

Por lo que respecta a Kant, Hegel valora enormemente la propuesta kantiana de la apercepción trascendental, puesto que sólo en ella se da la unificación de lo múltiple recibido en la intuición. Pero tal apercepción es la unidad de la conciencia del yo trascendental, que supera la experiencia, la representación y la conciencia empírica. Con todo, Hegel critica a Kant que de esta apercepción no halla podido sacar los conceptos como unidades totales de realidad y que sólo halla podido encontrar las categorías del intelecto como verdaderas y asequibles. Siguiendo a Kant, pero yendo más allá de él, Hegel afirma:

El objeto tiene esta objetividad en el concepto, y esta es la unidad de la autoconciencia en la que el objeto ha sido acogido; su objetividad, o sea ${ }^{32}$ Ibid., p. 254. el concepto, no es, por ende, otra cosa que la naturaleza de la autoconciencia, y no tiene otros momentos o determinaciones que el yo mismo. ${ }^{33}$

Así pues, Hegel lleva a su culmen las filosofías metafísicas que se basaron en la sustancia y en el sujeto respectivamente. Y tal superación se realiza en el concepto.

Hegel lleva a cabo una rigurosa exposición del concepto abarcando los momentos subjetivos, objetivos y su síntesis. Dentro del concepto subjetivo considera el concepto universal que es la totalidad en sí mismo, el concepto particular que incluye la determinación (concepto determinado) y el concepto individual que aporta la reflexión sobre sí mismo. Pero esto es sólo la cara interna del concepto que se exterioriza en el juicio y llega a su unidad en el silogismo.

Pero el concepto no es aún el final. Para Hegel el concepto aún tiene un lado meramente exterior que debe ser absorbido dialécticamente, hasta llegar a la idea, pues ésta "es la unidad de concepto y realidad". 34 La idea es la unidad de concepto y realidad que está en su absoluta inmediatez, pero por ello tiene todavía sólo el lado interno, tiene que desplegarse en la naturaleza y tal naturaleza debe acoger en sí la absoluta negatividad, dando lugar al espíritu.

${ }^{33}$ Ibid., p. 259.

${ }^{34}$ Ibid., p. 262. Cfr. también ibid., p. 294. 
Regresando al concepto, Hegel analiza la subjetividad del mismo en sus momentos de concepto, juicio y silogismo, lo cual presenta una cierta distorsión de la lógica clásica en la que los conceptos eran únicamente el material para síntesis mayores (juicio y raciocinio). Para Hegel, el concepto se niega a sí mismo en el juicio y se recupera a sí mismo en la negación de la negación que representa el silogismo. Además, el concepto tiene, en sí mismo, tres momentos: universalidad, particularidad e individualidad. Los tres momentos son siempre la totalidad del concepto. Hegel lo resume de la siguiente manera:

Como negatividad en general, o sea, según la primera, inmediata negación, lo universal tiene en sí la determinación en general, como particularidad; como segunda, como negación de la negación, es absoluta determinación o sea individualidad y concreción..$^{35}$

Con esto, Hegel lleva también a su culmen la distinción metafísica entre género, especie e individuo, ya que el concepto nunca es un concepto vacío o meramente formal, sino que posee en sí mismo la determinación de su contenido.

La vida, el yo, el espíritu, el concepto absoluto, no son universales sólo como géneros superiores, sino

${ }^{35}$ Ibid., p. 281. como concretos cuyas determinaciones no son tampoco sólo especies o géneros inferiores, sino tales que en su realidad, existen en absoluto solamente en sí y están llenos de sí. ${ }^{36}$

Al final, tenemos que "en el concepto, la identidad se ha desarrollado hasta convertirse en universalidad, la diferencia en la particularidad, la oposición, que vuelve al fundamento, en la individualidad". ${ }^{37}$

Hegel llega después del despliegue dialéctico del concepto a la idea que es vida, conocer e idea absoluta. La idea absoluta es el concepto que en la identidad consigo mismo abarca la vida como objetivación y el conocer como subjetivación de sí mismo. La idea universal es la unidad del concepto que abarca en la identidad consigo mismo la universalidad y la determinación. La idea absoluta es la unidad del concepto que abarca en la identidad consigo mismo la diferencia y la negatividad. Y por eso el concepto regresa a la vida, tal como ésta es entendida por Hegel y que señalamos más arriba: "sólo la idea absoluta es ser, vida imperecedera, verdad que se conoce a si misma, y es toda la verdad". ${ }^{38}$ Finalmente, Hegel explicita que el despliegue del ser en sí al ser en sí y para sí, alcanzado en el concepto, no es algo extrínseco a él mismo, sino una necesidad

\footnotetext{
${ }^{36}$ Ibid., p. 283.

${ }^{37}$ Ibid., p. 296.

${ }^{38}$ Ibid., p. 559.
} 
interna. Y esto lanza a Hegel a la caracterización del método, el cual no es otra cosa que "el concepto que se conoce a sí mismo, que tiene por objeto a sí mismo". ${ }^{39}$ Esto confirma lo que apuntamos al principio de nuestra exposición: para Hegel, lo absoluto debe estar al comienzo de todo y eso significa que el método es parte del absoluto que se expresa en momentos mediados dialécticamente. El método es, así, fundamentalmente analítico, si bien posee también momentos sintéticos que llenan de contenido lo universal formal que está al comienzo. ${ }^{40}$ La clave de todo está en la valoración y utilización del momento negativo o de la contradicción. Y aquí Hegel pasa nuevamente revista a la historia de la filosofía, poniendo como puntos culminantes a Platón y a la recuperación de la dialéctica por parte de Kant. Pero yendo más allá de Kant y anticipando una problemática posterior, Hegel afirmará la co-pertenencia de método y sistema, ${ }^{41}$ la cual también fue mencionada al inicio de esta exposición. En el método, en tanto el concepto que se piensa y se determina a sí mismo, Hegel ha alcanzado la consumación de la metafísica.

En el método absoluto, el concepto se conserva en su ser-otro, lo

${ }^{39}$ Ibid., p. 560.

${ }^{40}$ Cfr. ibid., p. 567.

${ }^{41}$ Nos referimos a la relación método-sistema en la fenomenología. universal se conserva en su particularización, en el juicio y en la realidad; en cada grado de ulterior determinación lo universal eleva toda la masa de su contenido precedente y, por su progresar dialéctico no sólo no pierde nada, ni deja nada tras de sí, sino que lleva consigo todo lo adquirido y se enriquece y se condensa en sí mismo. ${ }^{42}$

Así, aunque a la lógica deben seguir la filosofía de la naturaleza y la filosofía del espíritu, al final se "halla el supremo concepto de sí mismo en la ciencia lógica, como el puro concepto que se comprende a sí mismo". ${ }^{43}$

\section{Conclusiones}

Hegel, como ningún otro pensador antes y después de él, ha integrado la negatividad como momento dialéctico del ser mismo y, así, ha llevado a su culmen la empresa iniciada por los presocráticos, problematizada y nunca suficientemente solucionada por Platón y Aristóteles ni por la filosofía medieval, después atomizada en la filosofía moderna por el objetivismo de Spinoza y el subjetivismo trascendental kantiano: el problema del ser y del no-ser, el problema de la objetividad y la subjetividad, el problema de la relación entre concepto y vida.

${ }^{42} \mathrm{Hegel}$, Ciencia de la Lógica, op. cit., 2, p. 579.

${ }^{43}$ Ibid., p. 583. 
Hegel toma los puntos válidos de todas esas corrientes y los radicaliza en la idea absoluta como identidad en la diferencia y como diferencia en la identidad. Pero Hegel se mueve aún en la concepción metafísica de la realidad, es decir, Hegel está aún en el marco de la pregunta por el ente y no de la pregunta por el ser mismo en cuanto tal. Es así porque Hegel ve al ser aún como lo que encierra en sí la presencia, la apariencia y la cosa en sí. Claro está que resuelve la problemática de manera magistral y radical, pero siempre en ese marco dado desde antiguo. En una carta a Martin Heidegger, Max Müller afirma lo siguiente:

"Ser" es relegado a algún lado en toda metafísica, ya sea al lado más subjetivo del ens commune, de la ratio trascendentalis, de la "idea" de los más abarcador, etc., etc.; ya sea del ipsum esse, del absoluto presente y patente en todo; ya sea del ente en el que se esencia únicamente [...] Siempre estuve fascinado profundamente por la metafísica del idealismo alemán y me esforzaba por encontrar el punto en donde Hegel no acierta al asunto. Me pareció que el sujeto absoluto era una superación genuina de la contraposición sujeto-objeto. Sólo ahora veo que esta oposición no debe ser suprimida sólo posteriormente, sino ya debe estar superada originariamente [...] El ser no puede ser aprehendido ni como sujeto ni como objeto, sino como fuente pura, que deja surgir, anterior a la oposición sujeto-objeto. ${ }^{44}$

Así, Hegel lleva a cabo, posteriormente, la unidad de lo objetivo y lo subjetivo de parte del sujeto, como sujeto o espíritu absoluto. De ahí la afirmación de Eduardo Álvarez de que en Hegel se lleva a cabo una cierta antropologización de la metafísica:

De acuerdo con esta interpretación, el conjunto de la filosofía hegeliana resulta llevar hasta sus últimas consecuencias el planteamiento antropomórfico que se encierra en el origen de su pensamiento, a saber: la posición que toma a la conciencia humana como modelo para articular la ontología, posición que se pone radicalmente de manifiesto cuando se comprende la verdad del ser como concepto. En efecto, el gran proyecto especulativo de Hegel se elabora atribuyendo al ser en cuanto tal los procedimientos que la conciencia humana desarrolla cuando trata de captar las cosas y de comprenderse en su relación con ellas... De esta manera, el antropocentrismo de la filosofía moderna alcanza su fin, en un doble sentido: por un lado, porque el hegelianismo es la máxima expresión de esa

${ }^{44}$ Martin Heidegger, Cartas a Max Müller y Bernhard Welte. 2006, México, Universidad Iberoamericana, tr. Ángel Xolocotzi y Carlos Gutiérrez, p. 13-4. 
orientación filosófica y no parece que se pueda superar desde los supuestos de aquella metafísica; pero, por otro, porque se acaba con el proyecto moderno que él mismo ha llevado a su consumación, en cuanto hace aquí ya irreconocible algo esencial en la humanidad del hombre: su finitud, que todo el pensamiento posthegeliano no ha dejado de resaltar. ${ }^{45}$

Precisamente, Nietzsche y Heidegger serán dos de los pensadores que más insistirán en la finitud del hombre como base irrenunciable del nuevo comienzo de la metafísica.

Otro aspecto que nos lleva a ver en Hegel la consumación de la metafísica es la unidad (y superación en cuanto reducción) entre metafísica y lógica. Heidegger resume la tradición filosófica en cuanto olvido de la metafísica con las siguientes palabras: "La pregunta conductora determina desde los griegos hasta Nietzsche la misma manera de la pregunta por el 'ser'. El ejemplo más claro y máximo de esta uniformidad de la tradición es la Lógica de Hegel". ${ }^{46}$ Tal pregunta conductora puede verse con claridad en la forma que Platón desarrolla la dialéctica y la pone en relación con la ontología, y ésta a su

${ }^{45}$ Álvarez, op. cit., p. 175-6.

${ }^{46}$ Martin Heidegger, Aportes a la filosofia. Acerca del evento, 2003, Buenos Aires, Biblos, tr. Dina Picotti, p. 77. vez, con la lógica. A este respecto, Volkmann-Schluck escribe:

Las consecuencias de esta posición determinan el pensamiento desde Platón hasta hoy. En la época contemporánea el $\lambda$ ó $\gamma o \varsigma$ de la idea deviene concepto. El concepto capta lo múltiple en su unidad [...] que sujeto y objeto son lo que son recién a partir de la relación sujeto-objeto [...] Según Hegel en cuanto la subjetividad absoluta cuya esencia es el concepto absoluto, el absoluto $\lambda$ ó $\gamma \circ$ mismo [...] La filosofía del idealismo alemán es la esencial consumación histórica de aquello que inició con la posición de la idea de Platón. ${ }^{47}$

Así pues, si Hegel concluye su obra más especulativa, en tanto que consumación de la metafísica, con las siguientes palabras: "La lógica ha vuelto, en la idea absoluta, hacia aquella simple unidad que es su comienzo: la pura inmediación del ser", 48 entonces esta simple unidad se ha alcanzado de manera posterior y parece que no puede ser superada. Pero si la unidad debe ser ya alcanzada originariamente, entonces la lógica en cuanto metafísica debe tener otro comienzo, otro acceso, otro método.

${ }^{47}$ Karl-Heinz Volkmann-Schluck, Die Philosophie der Vorsokratiker, der Anfang der abendländischen Metaphysik, 1992, Würzburg, Königshausen und Neumann, p. 150. (Traducción mía).

${ }^{48}$ Hegel, Ciencia de la Lógica, op. cit., p. 249. 